\title{
PASTURE SEEDS MIXTURES, COMPETITION AND PRODUCTIVITY
}

\author{
W. HARRIS \\ Grasslands Division, D.S.I.R., Palmerson North
}

\section{INTRODUCTION}

The principles involved in making up a pasture seeds mixture are many and complicated, and while considerable attention was paid to these principles in the period between 1910-30 (e.g., Cockayne, 1914, 1917; Levy, 1923, 1936; Stapledon and Davies, 1927, 1928) development of other areas of investigation of sward performance have in recent years tended to overshadow the importance of the species mixture in determining the productivity of a sward.

In the establishment of pasture on bush-burns in the early stages of grasslands farming in New Zealand, it was common practice to include 20 species in a seeds mixture. Viewed in retrospect, such multi-species seeding was probably wise practice since there was little available knowledge to suggest which species would provide maximum productivity and cover in respect to climate, topography and soil. Pasture ecologists noted that, from these complex seeds mixtures, the succession from the established sowing led to the dominance of a few species in a homogeneous environment. Levy (1936) and others, working from these principles, suggested the simplification of mixtures, although some opposed this reasoning (Smith, 1936). Land development to produce an environment conducive to the maintenance of a simple perennial ryegrass/ white clover-dominant sward was indicated as the goal to grasslands attainment in New Zealand by Levy (1936).

\section{PRESENT-DAY MIXTURES}

Ryegrass was in all the mixtures and white clover was in all but two of the mixtures included in Table 1. These mixtures included an average of 3.9 species. For $17.8 \%$ of the mixtures, white clover was the only legume, indicating that the composition was predominantly two grass species plus two legumes. 
TABLE 1: PERCENTAGE OF SPECIES AS CONSTITUENTS OF 157 SEEDS MIXTURES FOR PASTURES 'SOWN IN THE SOUTHERN AREA OF THE NORTH ISLAND IN AUTUMN, 1968

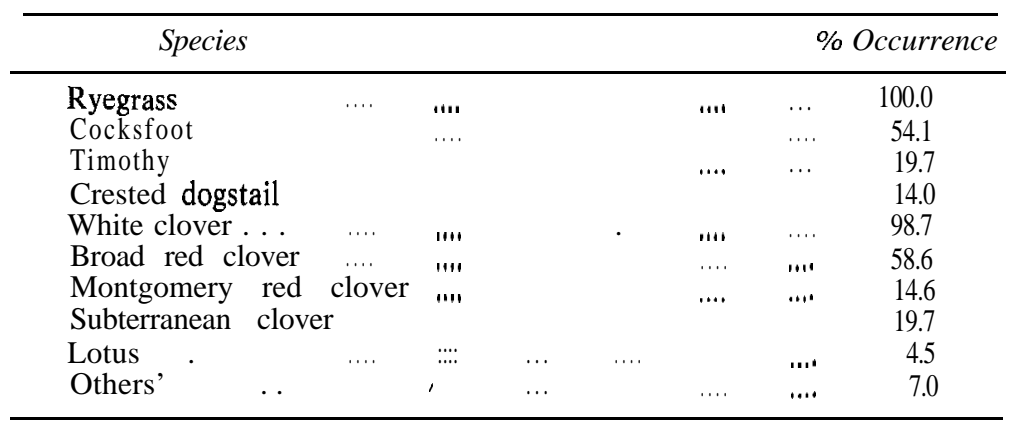

*Other constituents were turnips, S.17C fescue, alsike clover, strawberry clover, ryecorn, and chicory.

TABLE 2: MIXTURES OF FOUR RYEGRASS VARIETIES IN 157 PASTURE SEEDS MIXTURES

\begin{tabular}{|c|c|c|c|}
\hline $\begin{array}{c}\text { No. of } \\
\text { Varieties } \\
\text { in Mixture }\end{array}$ & & $\begin{array}{c}\% \text { Occurrence } \\
\text { of the } \\
\text { the Mixtures }\end{array}$ & $\begin{array}{c}\% \text { for the No. } \\
\text { of Varieties } \\
\text { Mixed }\end{array}$ \\
\hline 1 & $\begin{array}{l}\text { Ruanui (perennial) } \\
\text { Manawa }\left(\mathrm{H}_{1}\right) \\
\text { Paroa (Italian) } \\
\text { Ariki }\end{array}$ & $\begin{array}{l}8.3 \\
2.6 \\
1.9 \\
2.6\end{array}$ & 15.4 \\
\hline 2 & $\begin{array}{l}\text { Ruanui + Manawa } \\
\text { Ruanui + Paroa } \\
\text { Ruanui + Ariki } \\
\text { Manawa + Paroa } \\
\text { Manawa + Ariki } \\
\text { Paroa + Ariki }\end{array}$ & $\begin{array}{r}21.8 \\
11.5 \\
8.3 \\
0.6 \\
10.9 \\
1.3\end{array}$ & 54.5 \\
\hline 3 & $\begin{array}{l}\text { Ruanui + Manawa + Paroa } \\
\text { Ruanui + Manawa + Ariki } \\
\text { Manawa + Paroa + Ariki } \\
\text { Ruanui + Paroa + Ariki }\end{array}$ & $\begin{array}{r}5.8 \\
16.7 \\
0.6 \\
5.8\end{array}$ & 28.8 \\
\hline 4 & All 4 & 1.3 & 1,3 \\
\hline
\end{tabular}

Data compiled in Table 2 indicate that $84.6 \%$ of the mixtures included two or more ryegrass varieties. Of these, $90 \%$ were mixtures of persistent (Ruanui, Ariki) and nonpersistent varieties (Manawa, Paroa). 
Since blending of varieties of the same species can be viewed as undermining the usefulness of the end products of plant breeding programmes (cf. Rogers, 1966) presumably the variety mixer has some reasons. These could be :

(1) To increase productivity, perhaps by extending the period of growth.

(2) To ensure rapid cover to restrict weed ingress at sowing, at the same time including a persistent variety to form a permanent dominant of the established sward.

(3) To improve the quality of the sward herbage.

(4) To provide out-of-season growth.

(5) For safety and latitude

(6) Because of conservatism, or distrust of new varieties, interacting with curiosity about a novel material.

In a field experiment a Grasslands Division, Palmerston North, competition between Ruanui ryegrass, Manawa ryegrass, white clover and browntop (Agrostis tenuis Sibth.) was studied. Yield data collected were incorporated into a model of plant competition described by de Wit (1960) and further elucidated by Bakhuis and Kleter (1965) and de Wit et al. (1966). The results allowed a quantitative assessment to be made of the advantages or disadvantages, in terms of yield, arising from the mixing of species or varieties.

\section{INTERVARIETAL COMPETITION}

The replacement diagrams incorporating data for mixtures of Ruanui and Manawa ryegrass presented in Fig. 1 illustrate the competitive suppression of Ruanui by Manawa in the period immediately following autumn sowing. This resulted from the quicker establishment and greater cool season growth of Manawa. This effect was most marked with infrequent cutting, and resulted from the shading of Ruanui by Manawa which was able to elevate leaf to a higher level. The relationship between the crowding coefficients $(k)$ of the varieties in mixture indicates that the varieties "compete for the same space" which implies similar requirements for nutrients, light, etc., and similar periodicity of growth. This means that no ad- 


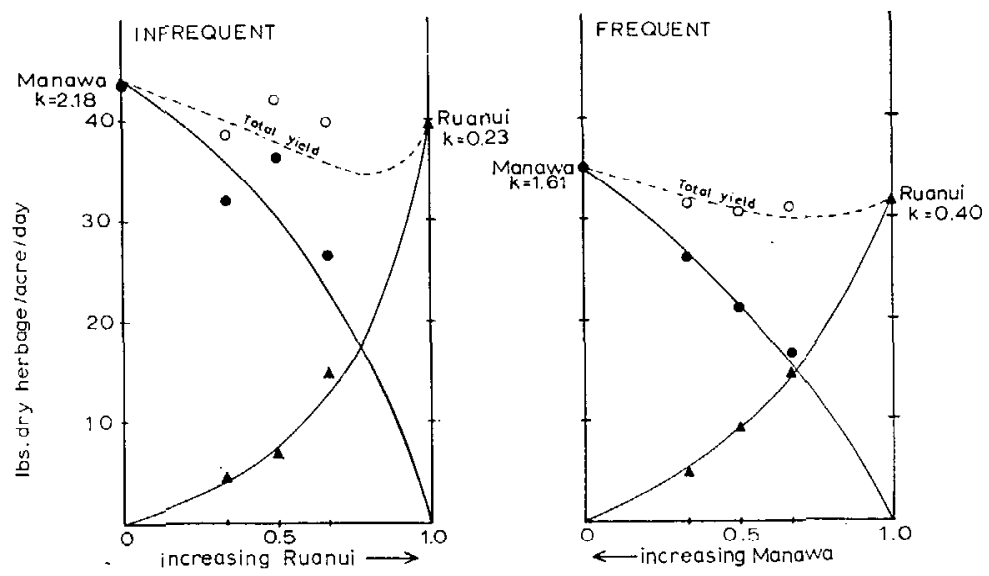

FIG. 1: Replacement diagrams based on yields of Manawa and Ruanui ryegrass for 29 weeks after sowing under frequent (5) and infrequent (3) cuffing.

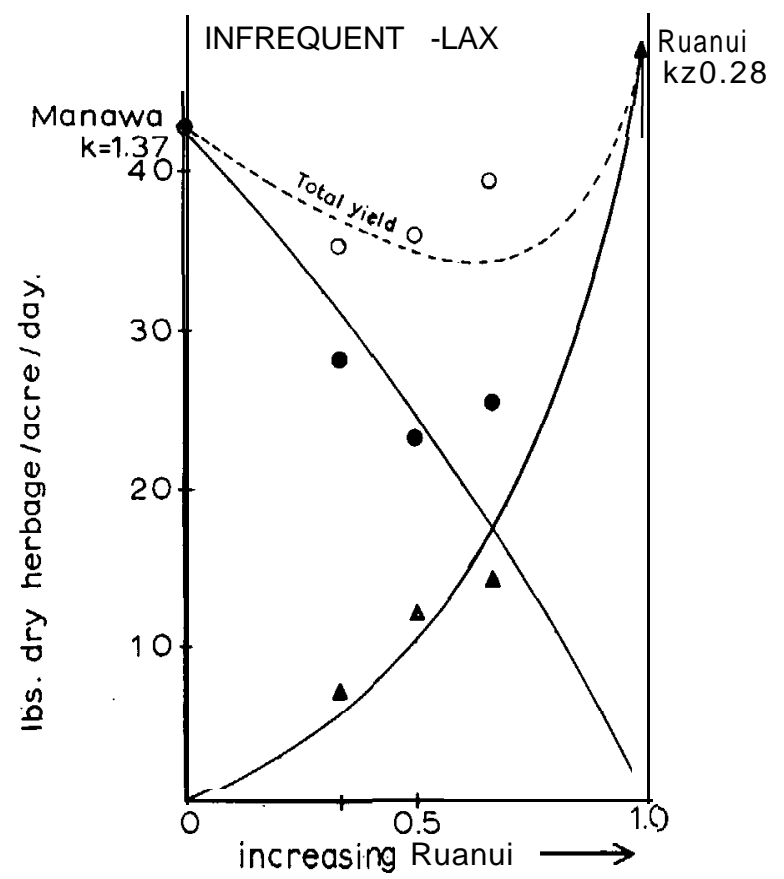

FIG. 2: Replacement diagram based on yields of Manawa and Ruanui ryegrass for 71 weeks after sowing. 
vantage in increased herbage yield is obtained by mixing, so that the greatest yield is obtained from the highest yielding variety grown in monoculture. Because of the gross genetic similarity of the various components of the Lolium perenne-Lolium multiflorum hybrid complex, re lated to overall similarities of growth requirements and periodicity of growth in the year after establishment, it can be predicted that in mixture these ryegrass varieties will for the greater part compete for the same space.

Total yield decreased where Ruanui and Manawa were mixed and defoliated laxly and infrequently for the first year (Fig. 2). This result is explained by the weakening and often killing of Ruanui plants by winter and spring shading from Manawa which hindered the transition to dominance of Ruanui in late summer.

Brougham and Harris (1967) showed that, in a Ruanui and Manawa mixture with white clover, under close continuous grazing for three years, Ruanui became the dominant ryegrass. Under lax rotational grazing, however, Manawa was the dominant variety. This experiment also demonstrated the persistence of Manawa, a variety variously examined for its lack of persistence (Lucanus et al., 1960; Brougham, 1961), under a defined system of grazing management, which was, however, clearly exclusive to Ruanui in the mixture. In an associated study (Harris and Brougham, 1968) it was implied that inclusion of Manawa in a permanent pasture seeds mixture, followed by continuous close grazing, particularly on areas of low to medium fertility, could hasten the ingress of browntop and other low producing species.

\section{COMPETITIVE SUPPRESSION OF UNDESIRABLE SPECIES}

The use of a fast growing cover crop in an autumn pasture sowing, in addition to providing winter feed (Brougham, 1954b), can also act to suppress weed species in the early phase of pasture establishment (Brougham, 1954C).

Results from the ryegrass-browntop mixtures demonstrated the greater suppression of browntop by Manawa than by Ruanui in the winter and spring following autumn sowing, particularly where defoliation was infrequent. This is demonstrated from the replacement diagram incorporating the total yields of the first year from infrequently and initially closely defoliated swards (Fig. 3). 
However, because of the lack of persistency of Manawa, spaces appeared in the sward in the second year which were filled by the horizontal spread of browntop. The ingress of browntop into the Ruanui swards was much less marked, particularly where the ryegrass content was initially high (Fig. 4).

Gains of yield can be obtained by mixing species. This results where the species of the mixture have different

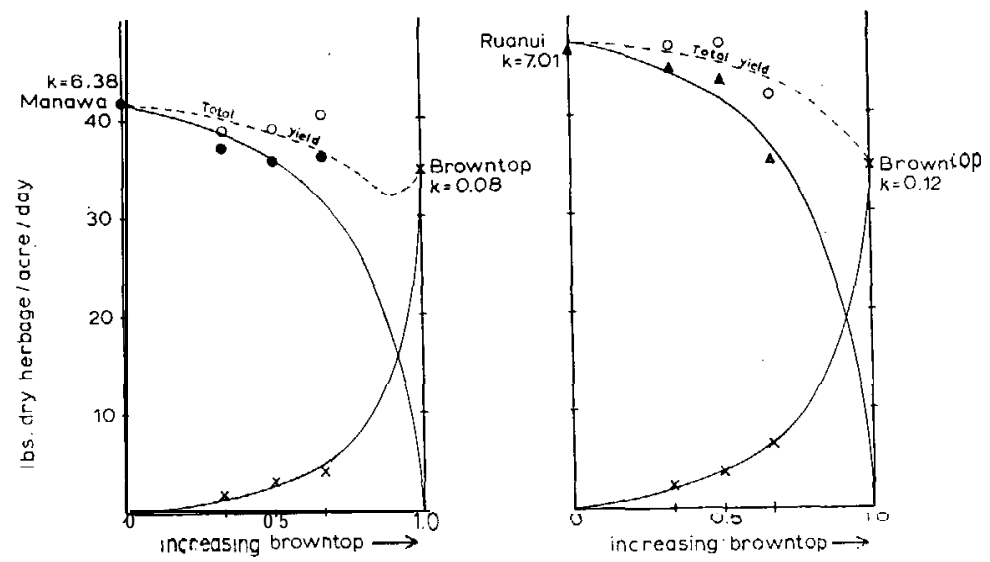

FIG. 3: Replacement diagrams based on yields of Manawa ryegrass, Ruanui ryegrass and browntop for 71 weeks after sowing.

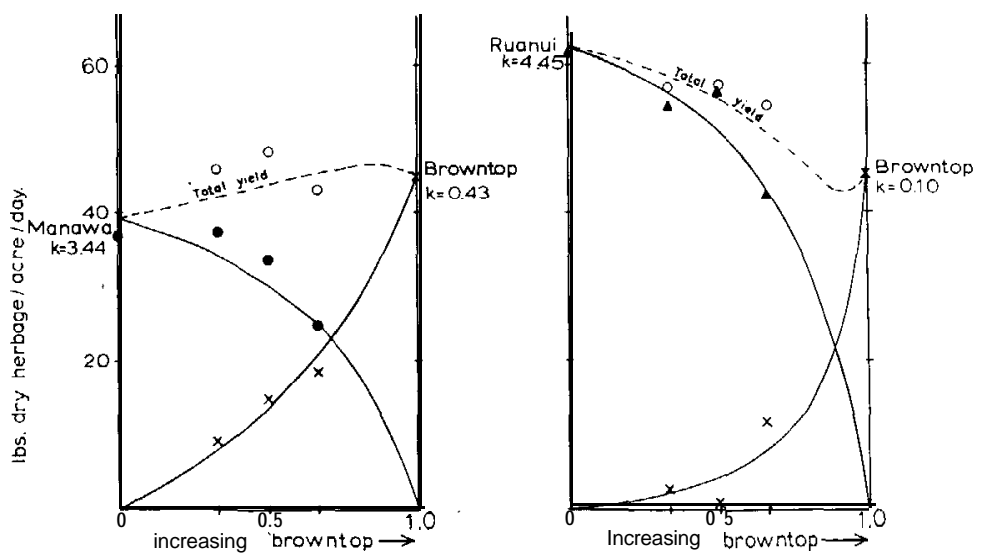

Fig. 4: Replacement diagrams based. on yields of Manawa ryegrass, $\mathrm{R}$ uanui ryegrass and browntop in the second year from August 21, 1967, to March 25, 1968. 
growth periods or where species utilize different nutrient sources by way of different rooting depths or nitrogen fixation. This type of competition is suggested in the diagram for the Manawa-browntop mixture in the second year (Fig. 4), and, although this may have resulted from differences of growth period or rooting depths, it is suggested that in this case it resulted, in part, from the contrasting habits of the two species. Morphologically, Manawa is able to utilize vertical space to a greater extent than browntop which has a well devasoped capacity for horizontal vegetative spread. Thus, where defoliation is irregular but tending to be infrequent, or in areas where there is a fertility mosaic caused by uneven return of nutrients, associated with stock avoidance of dung pad areas, a better utilization of space may occur with a mixture of "tufted" and stoloniferous or rhizomatous species. The ryegrass-white clover association is a mixture of the two habits.

\section{CONTROL OF THE GRASS-CLOVER RATIO}

One species of a mixture may profit by association with the other species to such an extent that its yield in mixture is greater than in monoculture. This can occur where
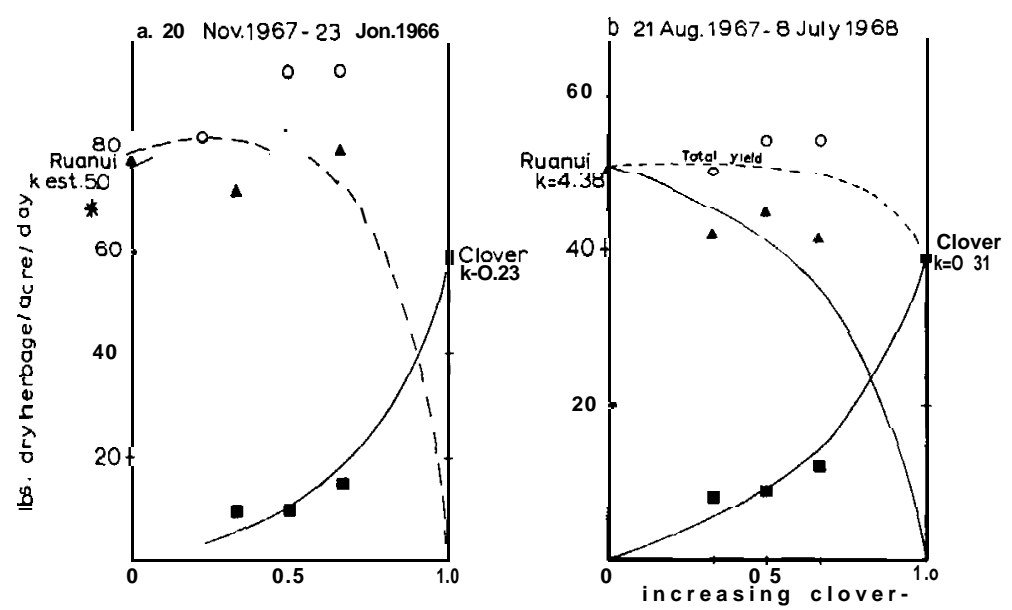

FIG. 5: Replacement diagrams based on yields of Ruanui ryegrass and white clover in the second year. ('Curve fitted assuming a linear increase of the monoculture yield in relation to an assumed linear increase of nitrogen supply with increasing clover.) 
clover nitrogen becomes available to associated grass, which subsequently becomes more competitive. This effect was demonstrated for a clover-Ruanui mixture in the early to mid-summer period of 1967-8 (Fig. 5a), when the growth rates of both clover'and grass were high and soil moisture levels were also high (cf. de Wit et al., 1966). Although Ruanui in mixture did not exceed the yield of Ruanui in monoculture for the total yield in the second year, it was indicated that the greatest total yield was obtained at a seeding rate which established a high clover content in the sward (Fig. 5b). This effect was also noted for the Manawa-clover mixtures in the first year and is comparable to the results of Brougham (1954a) with the same mixture. Since it has been demonstrated that greater sheep weight gains are obtained from white clover as opposed to ryegrass pastures (e.g., Clarke and Filmer, 1958; Lancashire and Keogh. 1966) it is implied that pastures of high yield potential both in terms of quantity and quality can be established with definable seeding ratios.

\section{CONCLUSIONS}

From the details of the ryegrass variety mixtures presented in Table 2, it could be concluded that many farmers' grass-seed requirements in the area surveyed would be met by seed of a hybrid swarm between Lolium perenne and Lolium multiflorum. This use of varieties is justified when it is considered that most new pasture varieties are released to the commercial market without precise definition of both the areas of their use and the management procedures to allow maximum survival and expression of their agronomically desirable features. While it is well reasoned policy to retain a considerable amount of genetic flexibility within bred varieties in New Zealand (Corkill, 1956), the fact remains that the creation of a variety inevitably limits the plasticity of the selected population in relation to that of the species as a whole. This implies a restriction in the range of environmental conditions in which a selected population can either survive, or produce the optimum yield. Accordingly, by considering the limits placed on a plant population's flexibility by selection, it is possible, for example, to define the area of use of Manawa as short- to medium-term pastures. in areas of evenly distributed rainfall and temperate climate, on medium to high fertility soils, where the grazing management is both rotational and lax. This corresponds with the breeder's assessment (Corkill, 1945). 
The writer is critical of the use of non-persistent varieties in mixtures for long-rotation or permanent pastures, particularly in areas of low fertility and continuous close grazing. While these varieties may produce additional feed in the establishment year, this advantage is counteracted by the demonstration that death of a sown component hastens the ingress of unsown species. Concentration on a persistent variety of ryegrass will ensure a greater ryegrass content in the sward for a longer period. When this increased ryegrass content is considered for the full area of a farm, and when it is considered, for example, that browntop has marked yield depressions during the critical yield periods of mid-winter and latesummer, a marginal increase of winter growth in the paddock of newly sown pasture on the farm is poor compensation for the after-effects.

Recently there have been predictions of a swing to artificial nitrogen-fed grass monocultures as a way to increased productivity. These predictions imply that the clover plant is valuable only for its ability to fix nitrogen. While nitrogen is undoubtedly the prime factor in the beneficial association of ryegrass and clover, it is also aided by the capacity of the two species to utilize the environment differently and so minimize interference. These differences include :

(1) Different times of peak growth.

(2) Different capacity for the utilization of horizontal as opposed to vertical space.

(3) Different leaf orientation and consequent light interception characteristics.

(4) Different rooting depths (Klapp, 1943; Jacques, 1943).

(5) Different water utilization patterns (Mitchell and Kerr, 1966).

These observations lead to the prediction that maximum plant community production, outside of artificial, homogeneous environments, will be achieved with mixtures of species, not with monocultures.

Increased precision in the formulation of pasture seeds mixtures will require greater attention to seed-bed preparation and weed control, mechanization for the precision planting of seed, attention to the competitive characteristics of species as related to the species with which they are to be combined, and consideration of this in breeding programmes involving the mixed species, and, finally, 
precision in management applied to the established pasture.

\section{ACKNOWLEDGEMENTS}

To Dr R. W. Brougham and V. J. Thomas for collaborative contributions, and B. A. Baker and N. E. Hibbard for technical assistance.

\section{R EFERENCES}

Bakhuis, J. A.; Kleter, H. J., 1965: Nsth. J. ogric. Sci., 13: 280.

Brougham, R. W., 1954a: N.Z. I. Sci. Tech., 35A: 518.

...., 1954b: Ibid., 36A: 47 .

-.., 1954c: I bid., 36A: 365.

... 19,61: N.Z. l. agric. Res., 4: 516.

Brougham, R. W.; Harris, W., 1967: Ibid., 10: 56.

Clarke, E. A.; Filmer, D. B., 1958: Ibid., 1: 249.

Cockayne, A. H., 1914: N.Z. J. Agric., 8: 233.

$$
\text { 1917: Ibid., 15: } 241 .
$$

Corkill, L., 1945: N.Z. J. A gric.. 71: 465.

---, 1956: Proc. 7th int. Grassl. Cong.: 427.

Harris, W.; Brougham, R. W., 1968: N.Z. J.agric. Res., 11: 15.

Jacques, W. A., 1943: N.Z.I.Sci. Tech., 25A: 91 .

Klapp, E., 1943: Pflanzenbau, 19: 221.

Lancashire, J. A.: Keogh, R. G., 1966: N.Z. J. agric. Res., 9: 916.

Levy, E. B., 1923: N.Z. J. Agric., 26: 261.

-.-, 1936: Ibid., 53: 270.

Lucanus, R.; Mitchell, K. J.; Pritchard, G. G., 1960: N.Z. J. agric. Res., 3: 185.

Mitchell, K. J.; Kerr, J. P., 1955: Agron. J., 58: 5.

Smith, J. M., 1936: N.Z. J. Agric., 53: 278.

Stapledon, M. A.; Davies, W., 1927: Welsh Plant Breed. Sta. Bull. Ser. H. 6: 64.

de Wit, C. T 1960: 1928: Ibid., 8: 162 pp.

de Wit, C. T., 1960: Versl. landbouwk. Onderz., 668: $82 \mathrm{pp.}$

de Wit., C. T.; Tow, P. G.; Ennik, G. C., 1966: Landbouw documenfatie, 687: $30 \mathrm{pp}$.

\section{DISCUSSION}

In reply to a question on the effect of the nutrient status of the soil on the competitive balance between species, Harris indicated that this was important. For the ryegrass-browntop mixtures, ryegrass would become more competitive with increasing soil fertility. For the ryegrass-white clover mixtures, the ratio giving the maximum yield would be determined by nitrogen availability, the white clover content increasing as nitrogen availability decreased. 
Questioned on the type of stand from which data were obtained, it was described that these were established on a wire-grid mesh giving a plant density of 16 plants per square foot.

When asked if the results described for the establishment period would apply later in the life of the pasture, Harris replied that they would in part, but added that there was a state of disequilibrium in the first year and that changes induced in this year could have a long-term effect on the productivity and botanical composition of a pasture.

The importance of. different leaf orientation in grasses and clovers had been emphasized and it was asked if this could be extended to grass mixtures. Harris replied that, if the grasses were sufficiently different in habit - i.e., with vertical and horizontal orientation - there could be advantages.

Asked about models to describe competition in mixtures of more than two species, Harris replied that at this stage these were not precise. It was stated that results from a series of two-species mixtures could be used to explain the complex competitive interactions involved in a multispecies sward. 